\title{
LA RESPONSABILIDAD MÉDICA DEL ESTADO O DE LOS PRESTADORES EN SALUD PRIVADOS DERIVADA DE PRÓTESIS MAMARIAS DEFECTUOSAS
}

\author{
José López Oliva*
}

Fecha de recibido: 15 de febrero de 2013

Fecha de aprobado: 18 de abril de 2013

Artículo resultado de investigación

Forma de citación: López, J. O. (2013). La responsabilidad médica del Estado o de los prestadores en salud derivada de prótesis mamarias defectuosas. Revista Prolegómenos. Derechos y Valores, 16, 31, 131-153.

\section{Resumen}

En los procedimientos de implantes mamarios de prótesis en cirugías plásticas estéticas o con fines reconstructivos, se pueden generar daños a los pacientes; daños generadores de perjuicios, que pueden presentarse como consecuencia del implante de prótesis defectuosas a los usuarios de los servicios de salud, que deben ser indemnizados por los prestadores de estos servicios o del ente estatal encargado de la inspección, vigilancia y control. Para proteger su patrimonio, los victimarios legitimados por pasiva y potenciales generadores de daños, pueden trasladar los riesgos inherentes de su actividad a una compañía aseguradora.

\section{Palabras clave:}

Paciente, prestador en salud, responsabilidad del Estado, evento adverso, cirugía plástica estética y reconstructiva, implante mamario, producto defectuoso, seguro, patrimonio.

\section{THE MEDICAL LIABILITY OF THE STATE OR THE PROVIDERS IN PRIVATE HEALTH DERIVED FROM DEFECTIVE BREAST PROSTHESES}

\begin{abstract}
Procedures of prosthetic breast implants, either as cosmetic plastic surgery or for reconstructive purposes, can cause damage to patients; because of defective prosthetic implants, damages that generate harm may arise to users of health services, which must be compensated by the providers of these services or the state agency responsible for inspecting, monitoring and controlling. To protect their assets, the perpetrators legitimized by passive and potential damage generators can transfer the inherent risks of their activities to an insurance company.
\end{abstract}

\section{Key words:}

Patient, health provider, state responsibility, adverse event, aesthetic and reconstructive plastic surgery, breast implant, defective products, insurance, estate.

* Profesor e investigador, Universidad Militar Nueva Granada. Director de la Línea de Investigación en Derecho de la Responsabilidad y de Seguros, UMNG. Magister en Derecho con énfasis en Derecho Privado Universidad de los Andes; Magister de la Universidad Carlos III de Madrid (España), Especializado en Derecho Comercial de la Universidad Pontificia Bolivariana de Medellín, Derecho Penal y Probatorio de la Universidad del Rosario; con estudios de doctorado en Derecho de la Universidad de Buenos Aires (Argentina); doctorando en Bioética médica y salud pública en la UMNG; profesor Universitario de pregrado, postgrado, conferencista a nivel nacional e internacional; profesor certificado a nivel internacional por la Life Office Management Asociation, Inc - Loma con sede en Atlanta-Georgia (USA). Correo electrónico: jose.lopez@unimilitar.edu.co 


\title{
A RESPONSABILIDADE MEDICA DO ESTADO OU DOS PRESTADORES DE SAÚDE PRIVADO DERIVADA DAS PRÓTESES DE MAMA DEFEITUOSAS
}

\begin{abstract}
Resumo
Nos processos de implantes mamários de próteses na cirurgia plástica estética ou para fins de reconstrução, que pode causar danos aos pacientes; danos geradores de prejuízos, que possam surgir como resultado de defeito no implante da prótese aos usuários de serviços de saúde, que devem ser compensados pelos prestadores destes serviços ou do órgão estadual responsável pela fiscalização, monitoramento e controle. Para proteger a sua riqueza, os vitimarios legitimados por passivos e potenciais geradores de danos, podem transferir os riscos da sua atividade para uma companhia de seguros.
\end{abstract}

\section{Palavras-chave:}

Paciente, prestadora de serviços de saúde, responsabilidade do estado, evento adverso, cirurgia plástica estética e reconstrutiva, implante mamário, produto defeituoso, seguro, patrimônio.

\section{INTRODUCCIÓN}

En el ejercicio de las actividades médico-sanitarias, se pueden ver transgredidos los derechos de los pacientes, como consecuencia de los daños generados por los prestadores en salud especialistas en cirugía plástica con fines estéticos o reconstructivos, al implantar prótesis defectuosas, producidas por compañías que desarrollan este objeto social; ante este hecho, la víctima puede demandar al prestador de los citados servicios de cirugía plástica, ente privado o público o, en su defecto, iniciar acciones judiciales en contra del Estado. Este último, potencial responsable por cuenta de la probable negligencia por omisión y la ausencia de las funciones de inspección, vigilancia y control de los productos utilizados en los citados procedimientos, y fabricados por empresas que están bajo la observación estatal.

El Estado, por medio del Instituto Nacional de Vigilancia de Medicamentos y Alimentos (INVIMA), establecimiento público del orden nacional y con carácter científico y tecnológico, tiene funciones relacionadas con la ejecución de las políticas y procedimientos de vigilancia y control sanitario sobre la calidad de los productos, en este caso las prótesis mamarias que son in- corporadas a los pacientes. El Estado puede ser condenado por cuenta de los daños causados como consecuencia de un evento adverso presentado en una institución pública o también demandado por inobservancia de los protocolos o negligencia por acción u omisión del INVI$\mathrm{MA}$, al otorgar licencias a productos que pueden llegar a ser catalogados como defectuosos.

Asimismo, a los prestadores particulares en salud se les pueden iniciar acciones legales, con el objetivo de obtener la reparación de los perjuicios causados con el implante de prótesis mamarias; prestadores privados que tienen la posibilidad de denunciar el pleito porque estos utilizaron un producto que estaba debidamente certificado por el INVIMA. Por ende, al proferirse el fallo condenatorio por parte del operador judicial en contra del demandado, puede verse vulnerado el patrimonio del victimario, sea este prestador sanitario del sector privado o público, como consecuencia del pago de la indemnización a las víctimas ordenada por el ente jurisdiccional; lo anterior, al exteriorizarse el riesgo generado en la ejecución de procedimientos quirúrgicos de cirugía plástica o estética, donde se pueden presentar eventos adversos productores de perjuicios. 
Los prestadores de salud particulares o estatales que realizan procedimientos quirúrgicos de implantes de mama defectuosos o los entes de vigilancia y control de productos para la realización de estos procedimientos, como se señaló con anterioridad, pueden ver comprometido su patrimonio. Lo precedente, porque pueden ser condenados por parte del funcionario judicial, perteneciente a la jurisdicción ordinaria civil o la jurisdicción contencioso administrativa. En ese sentido, se presenta el siguiente problema de investigación:

¿Es factible la protección del patrimonio de los prestadores públicos y privados en salud que causen daños al paciente al realizar implantes de prótesis mamarias, y la salvaguarda del patrimonio del INVIMA, quien puede certificar productos catalogados como defectuosos?

La hipótesis presentada como resultado de esta investigación, es que efectivamente existe la posibilidad de salvaguardar o proteger el patrimonio del Estado y de los particulares, potenciales responsables por los daños generados a los usuarios de los servicios de procedimientos quirúrgicos, destinados a implantar prótesis mamarias que pueden ser defectuosas; lo anterior, a través de la suscripción de una póliza de responsabilidad civil para prestadores en salud públicos o privados. Asimismo, las entidades del Estado como el INVIMA, tienen la posibilidad de suscribir a través de sus representantes legales una póliza de responsabilidad que cubra todos los posibles daños generados por la negligencia activa o pasiva de sus funcionarios o agentes.

Se evidencia, en la investigación realizada, que puede existir responsabilidad administrativa, con título de imputación subjetiva por falla en el servicio, por el incumplimiento de las funciones de vigilancia y control de las prótesis mamarias que resulten defectuosas. Dicho producto puede causar daños a los pacientes, generados por la posible negligencia por omisión de parte del INVIMA al certificar prótesis mamarias imperfectas las que, inclusive, pueden originar tumores mamarios en las mujeres a quienes se les realice el implante.
El presente texto es el resultado de una investigación de tipo exploratorio de reflexión, mediante la cual se indaga, compila, revisa $e$ integra el resultado de una revisión bibliográfica relacionada con temas de derecho médicosanitario civil y estatal, derecho de seguros, así como también derecho procesal, en el cual se involucran los derechos de los pacientes pero también el derecho cardinal de protección del patrimonio del potencial victimario; investigación en la que se identificaron, seleccionaron, agruparon y sistematizaron de manera temática y cronológica los documentos relacionados con la posible responsabilidad a cargo del Estado y de los particulares por los daños generados a los pacientes sujetos pasivos del evento adverso. El tema objeto de este trabajo es producto de la investigación terminada desde una perspectiva analítica, interpretativa y crítica, donde se presenta una propuesta; trabajo realizado en la Línea de investigación de Derecho de la responsabilidad y de seguros, perteneciente al grupo de Derecho Privado de la Universidad Militar Nueva Granada.

Para demostrar la hipótesis presentada, el texto se desarrolla de la siguiente manera: en primer lugar (1) se hace alusión a las víctimas de los procedimientos relacionados con implantes mamarios que pueden ser defectuosos y la vulneración de sus derechos, para enseguida (2) establecer los daños generados por dichos implantes y (3) analizar la responsabilidad de los profesionales que realizan los procedimientos antes señalados. A continuación, (4) se analiza el tema relacionado con la falla en el servicio por parte del Estado, (5) se identifican los posibles legitimados por pasiva y (6) se presenta la propuesta relacionada con la protección del patrimonio de los potenciales victimarios, a través de la póliza de responsabilidad civil para prestadores en salud públicos privados, y entes estatales encargados de las funciones de inspección, vigilancia y control respectivos. Para finalizar, (7) se presentan unas breves conclusiones o hallazgos de la investigación. 


\section{LAS VÍCTIMAS DE PROCEDIMIENTOS RELACIONADOS CON IMPLANTES MAMARIOS DEFECTUOSOS Y LA VULNERACIÓN DE SUS DERECHOS}

Los derechos a la vida, la salud e integridad física de las víctimas ${ }^{1}$, en este caso de los implantes mamarios defectuosos, está consagrado en diversos tratados internacionales $y$ regionales de derechos humanos, y en las constituciones de países de todo el mundo ${ }^{2}$, Organización Mundial de la Salud (OMS), como Colombia. Es relevante señalar, entonces, que las víctimas de los implantes mamarios defectuosos pueden ser los pacientes usuarios de los servicios de cirugía plástica con fines estéticos y reconstructivos quienes, de forma individual o colectiva, han sufrido lesiones de carácter físico o mental; víctimas a quienes se les han trasgredido sus derechos humanos ${ }^{3}$ (Organización de las Naciones Unidas), como la vida y la salud por parte del Estado, entre otras 4 , por la probable ausencia de inspección, vigilancia y control de productos a cargo de entidades estatales, como por ejem-

1 Para los fines del presente escrito, entiéndase víctimas, pacientes, beneficiarios del seguro, legitimados por activa y dañados como lo mismo, independientemente de su género.

2 La Organización Mundial de la Salud es un ente adscrito a la Organización de las Naciones Unidas (ONU).

3 La Organización de las Naciones Unidas (ONU), a través de la oficina del Alto comisionado para los Derechos Humanos, expide declaraciones con el objetivo de establecer los principios fundamentales de justicia para las víctimas, en este caso de eventos adversos, así como de los delitos y abusos de poder.

4 Otros potenciales causantes de daños son los profesionales liberales y las entidades públicas o privadas donde se realizan procedimientos de cirugías plásticas estéticas o reparadoras. Para los efectos de este escrito, tómese reconstructivas y reparadoras como lo mismo. Las estéticas, relacionadas con procedimientos para mejorar la apariencia física, la armonía y son consecuencia de la vanidad de la persona; las reparadoras se realizan con el objetivo de mejorar aspectos funcionales del paciente. Se hará referencia en el texto a los daños generados por los implantes realizados a mujeres, independientemente de que estos procedimientos se puedan realizar en el sexo masculino, amparados por derechos como la autonomía de la voluntad del paciente y el libre desarrollo de la personalidad. plo, el Instituto Nacional para la Vigilancia e Inspección de Medicamentos y Alimentos, en adelante INVIMA.

La Unión Europea, por ejemplo, empezó la búsqueda de la protección de los derechos de los consumidores con la salvaguarda de los derechos económicos, a la reparación integral de las víctimas, a la educación e información, y el derecho de ellos a ser oídos, catalogándolos como fundamentales. Es importante anotar que a la protección de los derechos a la salud y a la seguridad se les otorgó una especial preponderancia ${ }^{5}$ (Cuellar, 2012). Derechos que pueden ser vulnerados, como consecuencia de los daños generados por las prótesis mamarias generadoras de daños, implantadas en los pacientes.

El debate sobre los implantes de las prótesis mamarias, presuntamente defectuosas, ha generado controversia desde los aspectos jurídico, ético, moral y económico. El tema de las víctimas del daño médico-sanitario producido por los eventos adversos y generado por los citados implantes, ha alcanzado dimensiones considerables; víctimas que tienen la posibilidad de demandar al médico cirujano plástico con fines estéticos o reconstructivos, sea este del sector privado o público, o iniciar acciones judiciales en contra del Estado, por su probable negligencia por acción u omisión en las funciones de inspección, vigilancia y control, concretamente por parte del INVIMA. Los daños por legitimación activa según lo señalado por algunos sectores superan los trescientos mil en todo el mundo; aproximadamente "12.000, en España; 40.000, en el Reino en Unido; en Francia, 30.000; en Argentina,

5 En cuanto a la reparación integral de los perjuicios patrimoniales, esta deber debe ser integral, y debe garantizarse a todos los usuarios de la prestación médica que hayan sido lesionados en procedimientos quirúrgicos de implantes mamarios defectuosos, por ejemplo. La Declaración Universal de los Derechos Humanos señala que toda persona, en este caso el paciente, y su familia o causahabientes, tienen derecho a contar con una vida adecuada dentro del marco de una asistencia médica, salud y bienestar dignos. 
13.000; 62.500, en Venezuela, y en Colombia, 15.000" (Castro, 2012).

La víctima que provenga de procedimientos de cirugía plástica estética o con fines reconstructivos tiene derecho a la indemnización integral ${ }^{7}$ (Corte Constitucional de Colombia, 2009) de los perjuicios causados por el Estado, por su posible falla en el servicio de las funciones de vigilancia respectivas; mujeres víctimas catalogadas como usuarias o consumidoras de los servicios ${ }^{8}$ (Trigo \& Stiglitz, 1983) antes señalados, quienes están obligadas a realizarse procedimientos quirúrgicos destinados a retirar los implantes mamarios defectuosos, en algunas oportunidades las víctimas asumen los costos generados por dicho procedimiento. De ahí la importancia de la suscripción de una póliza de responsabilidad civil que cubra la indemnización que le corresponda pagar al prestador en salud o ente estatal, potencial dañador.

No es la primera vez que ocurre este tipo de eventos generadores de perjuicios a los pacientes o usuarios de los servicios médicos y sanitarios. En los años 60, en Alemania se presentó un escándalo de iguales proporciones por el uso del medicamento denominado Talidomida; medicamento utilizado para los malestares relacionados con el embarazo que al ser ingerido por las pacientes produjo degeneraciones irreversibles en el feto o también denominado nasciturus. Cincuenta años después de la ocurrencia

6 Cristina Castro en el periódico Ámbito Jurídico del 3 de febrero de 2012, el cual circula en Colombia, señala que, según información del periódico El País, existe una empresa productora de prótesis en Francia que está siendo investigada. En este texto, no se hace alusión a ninguna empresa en especial, sino de manera general a las empresas productoras de prótesis mamarias que pueden causar daños en el desarrollo de su objeto social, y de ahí la importancia de trasladar los riesgos inherentes a su actividad, a una compañía de seguros. Lo mismo ocurre con los entes estatales con funciones de inspección, vigilancia y control, así como los prestadores en salud públicos y privados.

7 El paciente víctima de daños médicos tiene derecho a la verdad, a la justicia y a la reparación integral, esta última catalogada como un derecho fundamental según lo señala el Magistrado Juan Carlos Henao Pérez.

8 El paciente es considerado en la actualidad como un consumidor de productos o servicios médicos. de este hecho, las prótesis mamarias "vuelven a demostrar que el control de los productos médicos y sanitarios debe ser muy riguroso y aplicado en cada país, individualmente. De no ser así, este efecto dominó volverá a suceder" (Castro, 2012). Efecto que lesiona los derechos del paciente, y en el cual las obligaciones relacionadas con la protección de su vida e integridad física recaen a cargo de Estado.

\subsection{La protección constitucional de los derechos de las víctimas de productos defectuosos}

La Carta Política colombiana dispone que "serán responsables, de acuerdo con la ley, quienes en la producción y comercialización de bienes y servicios atenten contra la salud, la seguridad y el adecuado aprovisionamiento a consumidores y usuarios" "Constitución Política de Colombia, art. 78), en este caso, de los servicios de salud.

La protección especial que le corresponde al INVIMA brindar a los usuarios de los servicios médicos, a quienes se les realizaron los implantes de prótesis de mama presuntamente defectuosa, debió obedecer a que "la responsabilidad en la contratación masiva se configura de una

9 Si bien es cierto se consagra la protección de los derechos del consumidor de los servicios médicos desde el punto de vista constitucional, existen disposiciones legales, como el Estatuto del Consumido,r que generan confusión en cuanto a dicha salvaguarda. Es así como Javier Tamayo Jaramillo señala lo siguiente: 'En la prestación de servicios en el que el prestador tiene una obligación de medios, la garantía está dada, no por el resultado, sino por las condiciones de calidad en la prestación del servicio, según las condiciones establecidas en normas de carácter obligatorio, en las ofrecidas o en las ordinarias y habituales del mercado'. Pero la norma solo arroja más confusión al asunto, pues la definición misma de obligación de medio que consagra no es clara. Además, en no pocas oportunidades, ni la ley, ni la doctrina ni la jurisprudencia, están de acuerdo sobre la naturaleza de las obligaciones en un caso concreto. Así, por ejemplo, en materia médica hay muchas obligaciones que son de medio y otras de resultado, sin que por ello se trate de soluciones pacíficas. Es más, no pocos autores desconocen la distinción entre obligaciones de medio y de resultado. Por lo tanto, el productor demandado, siempre alegará que su obligación es de medio, y por lo tanto, no tiene que probar una causa extraña para exonerarse" (Tamayo J. 2012, p.12). 
manera particular, toda vez que se parte de la base de que no hay igualdad entre los contratantes, como consecuencia de la asimetría de información, y de la imposibilidad del consumidor de obtener los medios probatorios que respalden sus pretensiones ${ }^{10 "}$ (Ibarra, 2012).

Consumidor de productos y servicios médicos, destinados a la implantación de las prótesis mamarias que pueden ser defectuosas, generadoras de perjuicios que deben ser resarcidos por el Estado. En suma, "si como consecuencia, bien de un mal funcionamiento del servicio o de su 'no funcionamiento' o del tardío funcionamiento del mismo se causa una lesión o un daño, el Estado es responsable y por consiguiente está en la obligación de indemnizar los perjuicios ocasionados ${ }^{11}$ " (Consejo de Estado de Colombia, 1967) en el caso de estudio, a los pacientes víctimas de los daños generados por los implantes que resulten averiados.

Así, la carta constitucional colombiana salvaguarda los derechos de las víctimas de los implantes mamarios que puedan resultar defectuosos, y si los prestadores en salud que causen daños con los implantes de las prótesis referidas no indemnizan a sus víctimas, ellas tienen la posibilidad de demandar el pago de los perjuicios al INVIMA. Por ende, el Estado puede ser responsable del pago de la indemnización por la falla en el servicio a cargo de la administración, originado en el deber primario de este, de "suministrar a los asociados los medios conducentes a la efectividad de sus servicios, a la consecución de sus fines; en otras palabras, a la realización del bien común"12 (Consejo de Estado de Colombia, 1967).

10 En relación con la protección del consumidor se puede inferir en el nuevo Estatuto que en algunos negocios jurídicos se constituye un verdadero contrato de adhesión, en detrimento de los intereses del consumidor de productos y servicios.

11 Perjuicios que pueden ser patrimoniales o extra patrimoniales, como se analizará más adelante.

12 Antes de consagrarse en la Constitución Política de Colombia el Estado social de Derecho, ya se establecía el deber del Estado por intermedio de los entes de control, de la salvaguarda de los derechos de los ciudadanos, en este caso, de los consumidores de productos y servicios.

\section{LAS PRÓTESIS PARA IMPLANTES MAMARIOS: PRODUCTOS QUE, AL SER DEFECTUOSOS, VULNERAN LOS DERECHOS DE LOS PACIENTES}

Existen, en la actualidad, compañías que pueden estar siendo investigadas por aparentes irregularidades en la producción de implantes mamarios. Implantes que fueron producidos por dichas compañías y que pueden llegar a ser catalogados como defectuosos y generar daños a los pacientes, a quienes se les vulneran sus derechos a la vida e integridad física ${ }^{13}$ (Alarcón, 2012).

Prótesis que en Colombia pudieron ser certificadas por el INVIMA y que podrían ser catalogadas como defectuosas porque según lo investigado, se pueden fragmentar cuando están dentro del organismo de la mujer, con la generación de los denominados eventos adversos ${ }^{14}$ (Ministerio de la Protección Social de Colombia, 2006), en materia de responsabilidad médico-sanitaria; mujer considerada víctima y beneficiaria de la póliza de responsabilidad civil para entes públicos y privados, a quien se le debe realizar un procedimiento quirúrgico de extracción de la citada prótesis de manera inmediata, con el objetivo de retirar el implante mamario dañado.

El producto defectuoso, en este caso las prótesis para implantes mamarios, es definido como aquel bien mueble corporal objetivo, "que en razón de un error en el diseño, fabricación, construcción, embalaje o información, no ofrezca la razonable seguridad a la que toda persona tiene derecho" (Congreso de la República de Colombia, 2011). El producto defectuoso rela-

13 Se están realizando estudios sobre implantes mamarios producidos en Europa a empresas a las cuales están siendo investigadas en la actualidad (Alarcón, 2012).

14 "Entendemos como eventos adversos a las lesiones o complicaciones involuntarias que ocurren durante la atención en salud, los cuales son más atribuibles a esta que a la enfermedad subyacente y que pueden conducir a la muerte, la incapacidad o al deterioro en el estado de salud del paciente, a la demora de dar de alta, a la prolongación del tiempo de estancia hospitalizado y al incremento de los costos de no-calidad. Por extensión, también aplicamos este concepto a situaciones relacionadas con procesos no asistenciales que potencialmente pueden incidir en la ocurrencia de las situaciones arriba mencionadas" (Ministerio de Protección Social, 2006). 
cionado con la seguridad sobre la condición de la prótesis mamaria presenta riesgos razonables para la integridad física, la salud y la vida de los consumidores; así, para establecer las condiciones de seguridad del producto, se debe tener en cuenta la duración del mismo, la información suministrada sobre el producto, la oferta acerca del servicio (Villalba, 2011) de implantación de la prótesis, y el control periódico de la misma.

Control periódico, porque las roturas del implante no se notan con facilidad en el organismo de la mujer, por lo tanto, se debe realizar de manera diligente ${ }^{15}$ (Trigo \& Stiglitz, 1983), un procedimiento denominado resonancia nuclear magnética ${ }^{16}$ (Adserá, 2013), con el objetivo de establecer la existencia de roturas en la prótesis implantada. Lo anterior, porque al romperse el implante se puede generar una reacción inflamatoria recurrente que puede producir un tumor en las glándulas mamarias, lo que vulneraría los derechos fundamentales a la salud ${ }^{17}$ (Galindo, 2011), a la vida (Corte Constitucional

15 La diligencia contraria a la negligencia como hecho generador de culpa debe imperar en el comportamiento del prestador sanitario, y en el productor de elementos que van a ser incorporados en el organismo de las personas.

16 "La Resonancia Magnética es una de las técnicas de diagnóstico por imagen más inocuas y modernas. Su funcionamiento se basa en ondas de radio que interaccionan con los átomos del cuerpo mientras están sometidos a un potente imán que rodea al paciente. El campo magnético del imán fuerza a los átomos de hidrógeno de los tejidos a alinearse en una dirección. Entonces, las ondas de radio que se envían hacia los átomos de hidrógeno resuenan. La máquina registra estas señales que se almacenan para ser procesadas por un ordenador. Los distintos tipos de tejidos del cuerpo devuelven señales específicas. La RMN permite obtener imágenes de gran precisión de distintas partes del cuerpo. Es de destacar, que la RMN no utiliza rayos X ni elementos radiactivos, por lo que no tiene efectos nocivos para el cuerpo. La duración de la prueba es de unos 30 a 60 minutos. Está supervisada en todo momento por un técnico especializado. Esta persona se encarga también de asegurarse que el paciente no tiene ni lleva ningún objeto metálico, como marcapasos, prótesis metálicas, reloj, gafas, etc. Hay que tener en cuenta que los objetos metálicos pueden interferir con el potente imán utilizado con esta máquina" (Adserá, 2013).

17 La protección integral significa que el Sistema de Seguridad Social en Salud debe atender la salud de la población en cuanto a la educación, información y fomento de esta, y la prevención, diagnóstico, tratamiento y rehabilitación, en cantidad, oportunidad, calidad y eficiencia. de Colombia, 1992; López, 2007) e integridad física del usuario del servicio de cirugía plástica estética o con fines reconstructivos.

Los implantes mamarios con indicios de ser defectuosos, si bien es cierto no pueden aparentar ningún defecto, deben retirarse como mecanismo de prevención para, posteriormente, colocarse las nuevas prótesis sin producir mayor traumatismo; sin embargo, si el implante está averiado se debe retirar y esperar el tiempo requerido por el médico, y proceder seguidamente a implantar una nueva prótesis. Procedimiento médico que es innecesario si el Estado, por medio del INVIMA, realiza sus funciones de inspección, vigilancia y control de manera diligente, salvaguardando con ello los derechos humanos y fundamentales, como se señaló, a la vida, salud e integridad física del paciente.

Para salvaguardar dichos derechos, si la "cápsula y prótesis no se retiran satisfactoriamente y la silicona se desparrama por la herida, es conveniente esperar para observar si el paciente desarrolla alguna reacción inflamatoria ${ }^{18}$ " (Hontanilla, 2012). Así, la relación de consumo que involucra a los pacientes, productores de prótesis mamarias, y prestadores en salud, puede constituir "una particular categoría que surge entre quienes se dedican profesionalmente a elaborar o proveer bienes o prestar servicios, con quien los adquiere con el fin de consumirlos" (Corte Suprema de Justicia de Colombia, 2009); por este hecho, al consumidor de productos $\mathrm{O}$ servicios médicos potencial dañado y destinatario final en la relación de consumo, se le debe proveer de una especial protección a cargo de instituciones estatales como el INVIMA.

La reacción inflamatoria, antes señalada, puede producir complicaciones en el estado de salud del paciente, y generarle perjuicios que pueden ser cubiertos por la póliza de responsabilidad civil para prestadores sanitarios; paciente usuario de los servicios médicos y beneficiario de la póliza, a quien se le pueden generar perjuicios

18 El tiempo de espera prudente para implantar una nueva prótesis sería entre 6 y 12 meses. 
que deben ser indemnizados por parte del Estado, por su probable falla en el servicio o por el asegurador si el ente estatal suscribió el citado seguro. Seguro de daños patrimoniales de responsabilidad civil que cubre las consecuencias del evento adverso generador de perjuicios, máxime cuando el hecho de retirar la prótesis mamaria dañada es un procedimiento traumático para el paciente que puede tener, inclusive, mayores implicaciones negativas que incorporar una nueva prótesis al organismo de la paciente.

Así, la víctima directa o indirecta del procedimiento de implante mamario debe ser reparada por los perjuicios patrimoniales ${ }^{19}$ y extrapatrimoniales ${ }^{20}$, causados como consecuencia del implante de un producto presuntamente defectuoso avalado por el INVIMA, por medio del procedimiento de cirugía plástica con fines estéticos o reconstructivos. Producto denominado inseguro porque "en situaciones normales de utilización, teniendo en cuenta su duración, la información suministrada sobre él y las condiciones en que ha sido instalado o mantenido, presenta riesgos irrazonables para la salud o integridad de los consumidores" (Robledo, 2013), en este caso pacientes víctimas de un producto defectuoso.

\subsection{La aplicación de la responsabilidad objetiva y la solidaridad, para la salvaguarda de los derechos del consumidor de productos y servicios de implantes mamarios}

Para proteger los intereses del paciente dañado, en las actividades médico-sanitarias rea-

19 Representados en el daño emergente y lucro cesante, los cuales pueden ser cubiertos por el seguro de responsabilidad civil para prestadores en salud.

20 También llamados inmateriales pero NO morales. Estos perjuicios se han clasificado en: morales, fisiológicos a la vida de relación o condiciones de existencia, psicológicos, estéticos y relacionados con la pérdida de la oportunidad. Si el asegurador cubre los perjuicios extrapatrimoniales, estará otorgando cobertura de todas las especies de este tipo de perjuicios; de lo contrario, si se señala en la póliza la cobertura de los perjuicios morales, solo se está cubriendo la especie, morales, del género, extrapatrimoniales, excluyendo los demás. En seguros, lo que no se incluye, automáticamente se excluye. lizadas por entes estatales y particulares, el tratamiento probatorio es diferente en lo que concierne a la carga de la prueba. Lo precedente, porque existe una "desventaja técnicocientífica frente la entidad pública (donde), hay una posición de inferioridad del particular en la prueba de las circunstancias que pueden rodear los acontecimientos que causan el perjuicio" (Guechá, 2012, p.102) a los pacientes.

El título de imputación de responsabilidad por culpa, o también denominada subjetiva a cargo del cirujano plástico estético o con fines reconstructivos, demanda de tres elementos que deben presentarse de manera concurrente: en principio el daño o evento adverso, denominación asignada en responsabilidad galénica, el cual debe evidenciarse en la víctima directa o los perjudicados indirectos, por contragolpe $e^{21}$ (Tamayo, 2005; Rojas, 2009), o causahabientes; en seguida, y como causa del daño galénico, debe presentarse un hecho doloso o culposo por parte del prestador en salud y, finalmente, se ha de establecer la relación de causalidad entre el evento adverso y el daño lesionador de bienes jurídicos tutelados por el Estado, como la vida e integridad física.

Con el objetivo de contrarrestar el desequilibrio contractual existente entre el consumidor de las prótesis mamarias posiblemente defectuosas, y el productor, comercializador así como el prestador del servicio, existen disposiciones normativas que incluyen la aplicación del régimen de responsabilidad objetiva. Este régimen de res-

21 El perjuicio por contragolpe, según Tamayo Lombana, hace referencia a lo siguiente:

Se sostiene en la doctrina que aun cuando haya transcurrido un solo instante entre las lesiones y la muerte, este instante es suficiente para que la víctima haya experimentado un dolor, lo que hace nacer en su patrimonio un crédito indemnizatorio. Si esto fue así, lo transmitirá a sus herederos. Son las reglas generales de la sucesión; los herederos son los continuadores de la persona del de cujus. Ellos estarán entonces legitimados para reclamar indemnización por este perjuicio moral sufrido por la persona fallecida. Actuarán en este caso como herederos. Estarán legitimados además actuando no ya como herederos sino en su nombre propio, para reclamar los correspondientes perjuicios materiales y morales ocasionados por el hecho o la culpa del demandado (Tamayo, 2005). 
ponsabilidad se aplica "a favor del consumidor, es decir, que a este no le será necesario probar la culpa del productor o del proveedor, sino únicamente el defecto del bien, por lo que el demandado solo podrá exonerarse de responsabilidad probando una causa extraña" (Ibarra, 2011).

En este caso, el productor o comercializador actuaría en calidad de tercero, porque al iniciarse el trámite judicial estos no fueron demandados por la víctima, por lo cual no tuvo, en principio, la calidad de parte. Una vez interviene el citado tercero de manera voluntaria por requerimiento del juez, o es convocado por el demandante o el demandado, se convierte automáticamente en parte e ingresa al litigio (Parra, 1992). Dentro de los terceros puede encontrarse el INVIMA, en el evento de ser demandado el cirujano plástico estético o reconstructivo o, en su defecto, la clínica u hospital donde se realizaron los procedimientos quirúrgicos de implante de las prótesis mamarias defectuosas. Entidad la cual hace parte de los terceros integrados por el principal, la coadyuvancia y los llamamientos oficiosos y en garantía (Bejarano, 1994).

Desde el punto de vista probatorio, existen normas que consagran el establecimiento de la inversión de la carga de la prueba en favor del consumidor de productos defectuosos, como los implantes mamarios. Los usuarios del producto con anomalías que lesionan tanto su integridad física como su vida, deben probar el deterioro de la prótesis que se encuentra dentro de su organismo. El demandante no necesariamente debe conocer o accionar en contra del productor del bien defectuoso, porque la ley (Congreso de la República de Colombia, 2011) le posibilita demandar al cirujano plástico ${ }^{22}$ (Tamayo, J., 2012) estético o con fines reconstructivos, por la expresa solidaridad existente entre productor,

22 Algunos tratadistas señalan que "es un craso error haber incluido los servicios médicos y de las profesiones liberales en general en un Estatuto del Consumidor donde la carga probatoria es la misma para todos los bienes o servicios. Lo razonable era haber dejado por fuera estos servicios o haber consagrado para ellos un régimen probatorio especial, claro y apropiado" (Tamayo, J., 2012). comercializador y profesional de la salud, quien suministró el producto dañado. Lo anterior, mediante la aplicación de las obligaciones plurales solidarias $^{23}$ (Código Civil colombiano, 2011) y la inaplicabilidad de las obligaciones conjuntas.

Asimismo, la solidaridad se presenta porque el INVIMA, como ente estatal encargado de la inspección, vigilancia y control de los medicamentos y alimentos que pretenden ingresar al mercado, es un ente administrativo que puede ser legitimado por pasiva en su globalidad; por esta razón, "no puede imputarse a tal o cual agente tomado en forma individual, sino al sujeto de derecho que institucionaliza este conjunto de estructura y de agentes" (Paillet, 2001, p.114). En consecuencia, el productor y el comercializador de las prótesis mamarias responden por los daños generados por el producto defectuoso, que pueden ser causados por ausencia de garantía o por los eventos adversos producidos por el producto con anomalías; este tipo de responsabilidad especial, plural y solidaria ha sido denominada como "responsabilidad de mercado" (Corte Constitucional colombiana, 2002).

23 El Código Civil colombiano señala que "Si un delito o culpa ha sido cometido por dos o más personas, cada una de ellas será solidariamente responsable de todo perjuicio procedente del mismo delito o culpa" (Código Civil de Colombia, 2011). En este caso, se estaría haciendo referencia a un litisconsorcio facultativo más no necesario. "el litisconsorcio significa pluralidad de partes en uno o en ambos extremos de la relación jurídica procesal, y admite tres clasificaciones: necesario, voluntario o facultativo y cuasinecesario. El litisconsorcio necesario se presenta cuando por la naturaleza de la relación jurídica sustancial no es posible adelantar ni concluir en el fondo el debate, si no están presentes todas las personas que conforman esa relación sustancial. El voluntario o facultativo se suscita cuando existiendo pluralidad de partes en uno o en ambos extremos de la relación jurídica sustancial, ella no es necesaria para el adelantamiento ni conclusión del proceso, dado que la relación jurídica sustancial de la que ha surgido el litigio contenido en el proceso, puede ser ventilada sin la presencia de todas las personas, quienes en consecuencia se consideran litigantes separados, pudiendo ser diverso el fallo para los litisconsortes. El litisconsorcio cuasinecesario, figura que para algunos no debe tener existencia autónoma, se predica de aquellas situaciones en las que no es necesaria la presencia en el proceso de todas las personas que conforman la relación sustancial que ha suscitado el litigio, pero con la particularidad de que el fallo que se profiera tendrá efectos contra todos, presentes y ausentes" (Bejarano, 1994). 


\section{LOS IMPLANTES MAMARIOS Y LA RESPONSABILIDAD DE LOS PROFESIONALES QUE REALIZAN PROCEDIMIENTOS DE CIRUGÍA PLÁSTICA, POR IMPRUDENCIA Y NEGLIGENCIA POR ACCIÓN Y OMISIÓN}

Se argumentó, con antelación, que puede existir responsabilidad del Estado con el título de imputación de responsabilidad subjetiva por falla en el servicio, ante la presunta ausencia de inspección, vigilancia y control a cargo del INVIMA; responsabilidad estatal, porque le corresponde al citado ente público, garantizar que los productos médicos, para el tema objeto de la investigación, no generen daños a los usuarios y consumidores de un producto que puede ser incorporado en el organismo del paciente.

No obstante, se evidencia que el precio de algunas prótesis es significativamente bajo $y$, por ello, algunos cirujanos plásticos se abstienen de implantar a sus pacientes las prótesis fabricadas por compañías que ofrecen prótesis excesivamente económicas o compañías que están siendo objeto de investigación por la producción de elementos que pueden ser catalogados como defectuosos. Lo anterior, porque dicha diferencia podría sugerir un indicio grave de mala calidad de las prótesis, aspecto que el INVIMA tiene que sopesar al momento de la expedición de la certificación correspondiente.

Así las cosas, según lo señalan algunos profesionales especializados en cirugía plástica con fines estéticos y reconstructivos, se trata de escoger las mejores marcas porque, como se indicó, el precio de las prótesis fabricadas por algunas compañías era "excesivamente reducido" (Hortanilla, 2012); este hecho puede generar duda o sospecha (Hortanilla, 2012) en los citados profesionales quienes al comparar los precios, se percataban de dicha situación, el cual puede representar una mala calidad del producto y, por ello, generar daños a las víctimas directas e indirectas del hecho médico generador de eventos adversos.

Al tener el producto un precio considerablemente bajo, se reducen los costos del procedimiento quirúrgico de implante mamario; en el caso europeo, por ejemplo, "si un implante cuesta 1.000 euros y otro 200, lógicamente el cliente escogerá el de 200, aunque hay cirujanos que directamente" (Hortanilla, 2012) se abstienen de utilizar este tipo de implante, por los riesgos que genera su incorporación en el paciente. Este hecho no podría argumentarse por parte del profesional en salud demandado en un proceso, como culpa exclusiva de la víctima del daño, en este caso el paciente a quien se le realizó el implante mamario y escogió, sin orientación alguna, el producto de menor costo.

Algunos profesionales de la salud señalan que es extraño encontrar cirujanos que incorporen al organismo del paciente prótesis elaboradas por empresas que actúan con aparente negligencia, porque tienen "una serie de marcas muy reconocidas y que llevan muchos años en el mercado, y fuera de ellas no se escogen otras" (Hortanilla, 2012), que posiblemente no otorgan una garantía del producto. Garantía aplicada a la producción, comercialización y distribución de servicios, incluidos los ofrecidos y facilitados por profesionales en cirugía plástica con fines estéticos y reconstructivos.

En suma, existe una relación de consumo entre los productores y comercializadores de las prótesis y el paciente, en la que se evidencia la citada relación, donde se establecen obligaciones de resultado $^{24}$ (Villalba, 2011), de seguridad y garan-

24 En cuanto a las garantías, se establece que son de dos clases: la primera, denominada legal y, la segunda, establecida como suplementaria. "El Decreto 3466 de 1982 contemplaba dos tipos de garantías diferentes, la garantía mínima presunta y la garantía convencional. La garantía legal, al tenor de la nueva ley, es la obligación que tiene todo productor o proveedor de responder por la calidad, idoneidad, seguridad y buen estado de funcionamiento de los productos (artículo 7). Además, el parágrafo de este artículo ratifica que la entrega o distribución de productos con descuento, rebaja o en promoción queda cobijada por esta ley, lo cual disipa cualquier duda acerca de la garantía de estos bienes, ya que en el comercio colombiano es muy frecuente encontrar afirmaciones como 'mercancía en promoción no tiene cambio'. Las garantías suplementarias son las otorgadas de manera adicional voluntaria por parte de los productores y proveedores (artículo 13). El término de la garantía legal, a falta de estipulación del proveedor o productor o de norma de obligatorio cumplimiento, es de un (1) año para productos nuevos y de tres (3) meses para productos usados" (Villalba, 2011). 
tía a cargo de los primeros; con lo anteriormente señalado, se puede aplicar a cargo del victimario la teoría de la responsabilidad por culpa presunta, donde le corresponde al dañador por intermedio del abogado asignado por el asegurador, demostrar su diligencia, prudencia y pericia en la elaboración o comercialización del producto.

Se puede evidenciar, entonces, imprudencia e inobservancia de los protocolos médicos por parte del prestador en salud especializado en cirugía plástica estética o reparadora pero, a la vez, se insiste, puede operar la negligencia por omisión en el organismo de inspección, vigilancia y control cuando se presenten indicios graves como los señalados anteriormente, que se deben tener en cuenta por parte del INVIMA al expedirse la respectiva licencia; esta, otorgada a los productores, distribuidores y comercializadores para la normal colocación en el mercado de un producto, el cual es incorporado en el organismo del paciente y puede generarle perjuicios ${ }^{25}$ (Robledo, 2013).

\section{LA FALLA EN EL SERVICIO POR PARTE DEL ESTADO, POR LA CERTIFICACIÓN DE PRÓTESIS MAMARIAS QUE PUEDE SER CATALOGADAS COMO DEFECTUOSAS}

LaLey 100 de 1993 crea el Sistema General deSeguridad Social en Salud (Congreso de la República de Colombia, 1993), el cual cambia y reorganiza

25 Hay que anotar que organismos como la Superintendencia de Industria y Comercio velan por la protección de los intereses de los consumidores, en este caso, de servicios médicos. Dicha Entidad "tiene entre sus funciones principales vigilar porque en el mercado circulen solo los productos que sean seguros. Por eso desde el año pasado se creó dentro de su estructura la Delegatura de Control y Verificación de Reglamentos Técnicos y Metrología Legal, que vela porque los productos sujetos al cumplimiento de reglamentos técnicos cuenten con los correspondientes certificados de conformidad emitidos por organismos acreditados en el país, y además verifica directamente las condiciones de seguridad de dichos productos. Igualmente, dentro de la Delegatura de Protección al Consumidor se creó el grupo de Seguridad de Productos, encargado de verificar las alertas que emiten las demás autoridades de protección al consumidor alrededor del mundo, y revisar los productos que consumimos los colombianos" (Robledo, 2013). la prestación sanitaria, la salud pública, el sistema de seguridad social y todo lo atinente a la provisión de servicios prestados por el sector privado.

En la citada ley se ordena la creación del Instituto Nacional de Vigilancia de Medicamentos y Alimentos INVIMA (Viceministerio de Salud, 1994), el cual es un "establecimiento público del orden nacional, de carácter científico y tecnológico, con personería jurídica, autonomía administrativa y patrimonio independiente, perteneciente al Sistema de Salud y con sujeción a las disposiciones generales que regulan su funcionamiento" (Ministerio de Gobierno de la República de Colombia, 1994).

Entre las funciones del INVIMA, como ente público del orden nacional y adscrito al Ministerio de Salud, se encuentran la ejecución diligente de las políticas relacionadas con la vigilancia sanitaria, y el control oportuno de la calidad de los medicamentos y productos como las prótesis mamarias, destinadas a ser implantadas en el organismo del paciente; funciones que al realizarse de manera negligente, puede generar responsabilidad del Estado ${ }^{26}$ (Constitución Política de Colombia, 2011) con título de imputación de falla en el servicio, como consecuencia de su actuar negligente por omisión.

Asimismo, al INVIMA, como ente público, le corresponde proteger los derechos a la salud, vida e integridad física de los pacientes, vigilar y controlar la calidad de los productos biológicos, alimentos, bebidas, cosméticos, productos odontológicos y elementos médicos utilizados para procedimientos quirúrgicos como los implantes mamarios; de la misma forma, son objeto de inspección y vigilancia por parte del INVIMA, los productos homeopáticos natura-

26 La Constitución Política colombiana señala que "El Estado responderá patrimonialmente por los daños antijurídicos que le sean imputables, causados por la acción o la omisión de las autoridades públicas. En el evento de ser condenado el Estado a la reparación patrimonial de uno de tales daños, que haya sido consecuencia de la conducta dolosa o gravemente culposa de un agente suyo, aquél deberá repetir contra éste" (Constitución Política de Colombia, 2011). 
les o generados a través de la biotecnología, así como los reactivos de diagnóstico que puedan generar impacto negativo para la salud individual o colectiva de las personas, en este caso de los usuarios de las prótesis mamarias.

Igualmente, dentro de las funciones del INVIMA está la de vigilar la calidad de los productos, verificar la respectiva importación y comercialización del producto, medicamento o alimento que va a ser comercializado. Al fallar el Estado y concretamente el INVIMA en sus funciones, las víctimas de las prótesis mamarias pueden demandar de manera directa la reparación del daño ${ }^{27}$ (Código Contencioso Administrativo, 2011), por la omisión de los protocolos de inspección, vigilancia y control respectivos, obligaciones a cargo del citado ente gubernamental.

Los antecedentes de la falla en el servicio y su incorporación en las disposiciones colombianas se remontan al derecho francés, como consecuencia de la obligación del Estado de indemnizar los daños generadores de perjuicios causados por este, en el caso de la investigación por entidades públicas como el INVIMA. Indemnización integral impuesta al Estado y en favor de los pacientes, por errores que generan un daño antijurídico resultante de su funcionamiento anormal (Saavedra, 2005).

En relación con la falla en el servicio generadora de daños por parte del INVIMA, esta ha sido clasificada en cuatro tipos: la falla probada en el servicio, la falla en el servicio anónima, la falla presunta del servicio y por último la falla relativa del servicio. En la falla probada del servicio a cargo del Estado, le incumbe probar a la víctima que el hecho dolo-

27 El Consejo de Estado de Colombia ha establecido que "cuando se trata de lesiones que producen alteraciones físicas que afectan la calidad de vida de las personas, estas tienen derecho al reconocimiento de una indemnización adicional a la que se reconoce por el perjuicio moral; es decir, el reconocimiento de esta clase de perjuicios no deben limitarse a los casos de lesiones corporales que producen alteraciones orgánicas; sino que debe extenderse a todas las situaciones que alteran de manera grave las condiciones habituales o de existencia de las personas" (Consejo de Estado de Colombia, 2011). so o culposo de un agente del Estado, fue causado por su negligencia por hacer o dejar de hacer.

La falla anónima del servicio está relacionada con el acto dañoso causado por el ente estatal, el cual no es producido por una persona física concreta ${ }^{28}$ (Ruiz, 2010, Consejo de Estado, 2009) determinada o determinable; no obstante, el hecho de no identificarse la persona física generadora del daño, no significa en esta modalidad de responsabilidad subjetiva que el Estado, para el caso de la investigación el INVIMA, no le corresponda la obligación de indemnizar a la víctima, por la ausencia de inspección, vigilancia y control de productos defectuosos como los implantes mamarios, por ejemplo.

En la falla presunta del servicio a cargo del Estado se presume la falla (culpa-régimen subjetivo) de este, quien tiene que desvirtuarla con el aporte y práctica de pruebas pertinentes y conducentes, con el objetivo de exonerarse de su responsabilidad. La falla presunta en la que puede incurrir un funcionario del INVIMA "indica una actuación de la administración donde se presume la actuación irregular, es decir, se releva al particular de demostrar el funcionamiento anormal del servicio, y en estas circunstancias se considera que la entidad pública ha vulnerado principios de buen servicio público" (Guechá, 2012, p. 101).

Ante la falla presunta del servicio por parte del Estado, este debe responder patrimonialmente por los daños antijurídicos que le son imputables, como consecuencia de la posible negligencia por omisión por parte del INVIMA, en su calidad de autoridad pública (Olano, 2011) con funciones de inspección, vigilancia y con-

28 El Consejo de Estado de Colombia ha establecido que "la falla del servicio es anónima, para indicar que no se requiere establecer en el proceso quien fue el autor material del daño causado; pero esto no significa que no deba establecerse los hechos a partir de los cuales se pretende imputarle al mismo ese daño; por lo tanto, no era necesario que en este proceso se identificara a la persona que dio muerte al menor, pero para poder imputar ese hecho a la Nación, por haber sido causado por un agente a su servicio sí era necesario acreditar esa circunstancia" (Consejo de Estado, 2009). 
trol; funciones, las cuales pueden realizarse de manera parcial y que eventualmente están alejadas de los protocolos pertinentes.

La responsabilidad del Estado se evidencia porque es a este, a través del INVIMA, a quien le corresponde reglamentar todo lo atinente al régimen de registros, así como la expedición de licencias, la vigilancia y el control sanitario de productos (Congreso de la República de Colombia, 1993) como los implantes mamarios que puedan resultar defectuosos, los cuales generarían daños a los pacientes. Si bien es cierto los cirujanos plásticos ${ }^{29}$ (Le Tourneau, 2005) deben advertir que el precio de las prótesis puede ser directamente proporcional a la calidad del producto, está a cargo de los servidores públicos del INVIMA ejercer de manera diligente sus funciones y no actuar con negligencia por omisión (Olano, 2011) en el desarrollo de las mismas, al certificar productos que pueden generan daños.

En suma, el INVIMA debe adelantar los estudios pertinentes de las prótesis mamarias de manera diligente, máxime cuando se puede comprometer el derecho humano y fundamental a la salud, la protección de la dignidad humana ${ }^{30}$ (Macklin, 2009, Corte Constitucional, 1992) e integridad física de las víctimas de los implantes mamarios. Este establecimiento puede expedir

29 El prestador en salud debe instruir, informar y advertir al usuario de sus servicios, sobre los procedimientos que se van a realizar sobre su cuerpo y acerca de los productos a implantar en su organismo.

30 Modelo de Estado que se funda en "el respeto de la dignidad humana y tiene como uno de sus fines esenciales garantizar la efectividad de los principios y derechos" (Corte Constitucional de Colombia, 1992). Existen procedimientos médicos derivados de investigaciones científicas que pueden lesionar la dignidad del paciente. Es el caso de los procedimientos de reproducción asistida; se señala respecto a este tema que (...) appeals to human dignity populate the landscape of medical ethics. Claims that some feature of medical research or practice violates or threatens human dignity abound, often in connection with developments in genetics or reproductive technology. But are such charges coherent? Is dignity a useful concept for an ethical analysis of medical activities? A close inspection of leading examples shows that appeals to dignity are either vague restatements of other, more precise, notions or mere slogans that add nothing to an understanding of the topic (Macklin, 2009, p. 1420). los registros sanitarios pertinentes de prótesis que puedan ser catalogadas como defectuosas, con las vigencias señaladas para dicho producto, de acuerdo a lo establecido por la ley (Congreso de la República de Colombia, 1993). La consecuencia de esta expedición puede ser la generación de daños a los pacientes víctimas de los implantes mamarios defectuosos, generadores de eventos adversos que no contribuyen al bienestar del paciente, concretamente de los procedimientos de cirugía plástica reparadora o con fines reconstructivos.

En este orden de ideas, el Estado puede ser responsable de los daños generados a los usuarios de los servicios de implantes de prótesis mamarias, quienes son víctimas sobre las cuales se materializa la conducta dañosa ${ }^{31}$ (Corte Constitucional de Colombia, 2002). Lo anterior, por su posible negligencia al omitir los protocolos de inspección, vigilancia y control, debido de los productos defectuosos sobre los cuales puede otorgar licencia sanitaria, sin calcular los costos (Calabresi, 1961) $y$ riesgos que este hecho puede generar.

Es importante señalar, que existen riesgos de producir daños a los usuarios de los servicios y productos destinados a ser incorporados al organismo de la persona; estos riesgos pueden ser trasladados a una compañía aseguradora a cambio del pago de una prima, y de esta manera proteger el derecho al patrimonio del Estado, en su calidad de ente certificador de productos y servicios, así como la protección de los activos de los prestadores en salud públicos o privados potenciales dañadores; asimismo, se garantiza, con la suscripción de la citada póliza, el derecho fundamental a la reparación integral de las víctimas de los implantes mamarios defectuosos. Así lo enuncia Fernández:

31 La alta Corporación al hacer referencia a las víctimas y los perjudicados hace la siguiente reflexión: "A partir del año 2002, definió claramente lo que se debía entender por víctima... (y)...perjudicado... Según el alto Tribunal, victima (es la persona respecto de la cual se materializa la conducta...), perjudicado (tiene un alcance mayor en la medida en que comprende a todos los que han sufrido un daño así no sea patrimonial (...)" (Corte Constitucional de Colombia, 2002). 
La finalidad de protección de las victimas explica en gran medida el desarrollo prodigioso que ha tenido el seguro RC. Desarrollo que, a su vez, se debe a la toma de conciencia acerca de la importancia y la gravedad del riesgo de responsabilidad civil en el mundo moderno. Además, la ocurrencia de riesgos de accidentes, resultado del carácter peligroso de una gran numero de actividades, ha multiplicado las posibilidades de que sea puesta en tela de juicio la responsabilidad civil, incitando a que el legislador y la jurisprudencia pongan en marcha sistemas de responsabilidad mucho más estrictos, lo que a su vez conlleva a que los potenciales responsables se vean en la necesidad de contratar un seguro ( 2008).

\subsection{Caso práctico analógico entre el tema objeto de investigación y la respon- sabilidad por producto defectuoso}

Se hace alusión en seguida de manera breve, a un evento por producto defectuoso, el cual fue fallado por la Corte Suprema de Justicia de Colombia, con el objetivo de realizar una analogía entre este y el presentado en la investigación, como objeto de estudio. Lo anterior con el único propósito de establecer la existencia de responsabilidad del Estado o de prestadores en salud particulares, ya que, para que exista responsabilidad, debe presentarse un hecho, un daño y una causa del mismo, es decir, un nexo de causalidad. Hay que anotar que tanto al Estado como a los particulares les asiste un derecho constitucional de acción en vía de contradicción, representado en los eximentes de responsabilidad, con el propósito de desligar el nexo causal entre el hecho dañoso, el implante mamario, y el daño productor de perjuicios patrimoniales y extrapatrimoniales.

En este orden de ideas, existe la posibilidad de que al Estado o a los particulares prestadores en salud, no les asista responsabilidad por inexistencia del nexo de causalidad.

El caso es el siguiente: la señora Margy María Manasse Vargas demanda la reparación de perjuicios causados por la empresa lechera "La Alquería
S.A", solicitando que se declare extracontractualmente responsable a la citada sociedad, por la significativa disminución visual que constituye el daño, causado por el consumo de leche contenida en una bolsa, producida por la parte pasiva del proceso.

En este caso, no se logró relacionar la pérdida de la visión de la demandante, establecida como el daño, con la causa del mismo, el consumo del producto, configurándose el denominado rompimiento del nexo de causalidad entre el hecho dañoso y el daño generador de perjuicios.

La Corte señaló que la enfermedad sufrida por la demandante denominada desmielinización ósea, podría ser causada por aspectos genéticos y no por el consumo del producto comercializado por la empresa demandada. Esta enfermedad crónica que produce trastornos sensoriales y perturbaciones en el control muscular, por la degeneración de las vainas de mielina de las fibras nerviosas (Dudgale, 2011), no se presentó en ningún otro consumidor del lote de leche producido por la demandada.

No obstante, en la investigación realizada, se advierte que el hecho generador del daño puede producir perjuicios a las pacientes, a quienes se les implanten prótesis mamarias defectuosas. En este caso, al contrario del expuesto, el hecho que genera el daño puede producirse como consecuencia de la negligencia por omisión a cargo del INVIMA o la responsabilidad del prestador en salud privado o público.

Por ende, la actividad de los jueces no puede centrarse en posiciones individualistas de los empresarios que producen prótesis, por ejemplo, porque la autonomía de la voluntad privada de las empresas no puede lesionar los intereses del usuario del servicio médico, a quien se le puede implantar una prótesis que puede resultar defectuosa; por lo tanto, "se eleva la necesidad de imponer equilibrio donde por fuerza de la naturaleza o de las circunstancias no lo hay" (Corte Suprema de Justicia, 2009), por medio de normas y sanciones que pueden estar dirigidas al INVIMA o al prestador sanitario público o privado que puede generar daños. 


\section{LOS LEGITIMADOS POR PASIVA DE LA RESPONSABILIDAD POR LOS DAÑOS GENERADOS POR LAS PRÓTESIS DEFECTUOSAS}

Es relevante identificar, en principio, el tipo de responsabilidad en que puede incurrir el productor, distribuidor, comercializador y el profesional de la salud que realiza un procedimiento quirúrgico al paciente, destinado a implantar una prótesis catalogada como defectuosa; responsabilidad que puede ser de índole civil, administrativa, penal o ético disciplinaria; en seguida, es pertinente identificar el régimen de responsabilidad al cual puede ser sometido el dañador, sea este subjetivo o también denominado régimen de culpa presunta o probada, u objetivo con presunción de responsabilidad $^{32}$ (Tamayo, 2005), donde la citada culpa como factor subjetivo inmaterial, es irrelevante.

Asimismo, hay que señalar que en la presente investigación se hace expresa alusión al tipo de responsabilidad civil y del Estado, con el argumento de que a este último, le puede asistir responsabilidad generada como consecuencia de la negligencia tanto por omisión como por acción, concretamente a cargo del INVIMA.

La responsabilidad civil por parte de los importadores de las prótesis mamarias defectuosas se puede producir como consecuencia de introducir al país un producto que vulnera la seguridad, integridad física y la vida de los consumidores; en este orden de ideas, los fabricantes y proveedores enfrentan, en cuanto empresarios profesionales, un probable juicio de imputación de responsabilidad, fundado, primordialmente, en el hecho de poner en circulación un producto defectuoso"

32 La teoría del riesgo procede en las actividades denominadas "peligrosas" donde se aplica el régimen objetivo de responsabilidad, y se resume en el hecho de que al generar un riesgo para la comunidad y lucrarse del mismo, una vez exteriorizado éste, el victimario está obligado a reparar los perjuicios causados a consecuencia del daño. El demandado responde en este tipo de responsabilidad sin que sea recurrente el elemento "culpa". El demandante únicamente establece el hecho dañoso y el perjuicio generado, no correspondiéndole establecer el nexo causal entre estos dos elementos de la responsabilidad (Tamayo, 2005).
(Corte Suprema de Justicia de Colombia, 2009) lesionador de los derechos de los pacientes.

La víctima tiene la posibilidad de demandar al productor de las prótesis mamarias defectuosas, por cuanto dichos implantes no pueden tener los estándares mínimos de seguridad que se esperaban. Asimismo, puede estar legitimado por pasiva, el distribuidor de las prótesis que pueden resultar defectuosas, "si fue él quien por negligencia suya generó el defecto del producto u omitió las revisiones de seguridad pertinentes antes de ponerlo en circulación (culpa por omisión)" (Corte Suprema de Justicia de Colombia, 2009).

Las obligaciones de seguridad hacen presumir la culpa del deudor, en este caso del productor de las prótesis mamarias que se cataloguen como defectuosas, quien puede exonerar su responsabilidad probando la fuerza mayor, la culpa exclusiva y determinante de un tercero y la culpa de la víctima accionante en el litigio ${ }^{33}$ (Corte Su-

33 La Corte Suprema de Justicia ha establecido que en el caso de las demandas derivadas de los daños causados por productos defectuosos, el legitimado por pasiva puede argüir la ocurrencia de una "fuerza mayor, en cuanto acontecer imprevisible e irresistible totalmente ajeno al empresario o a su actividad), el hecho exclusivo de la víctima o de un tercero (hipótesis que está circunscrita a los eventos en los que el producto es puesto en circulación por personas ajenas al productor, o manipulado por éstas), exoneran al fabricante y a los proveedores. Si bien no es esta la oportunidad para desarrollar con amplitud el punto, es conveniente precisar que el hecho que puede aducir el demandado como constitutivo de fuerza mayor debe ser totalmente externo a su órbita de control, peculiaridad que, para decirlo con franqueza, podrá ser poco usual en la materia. Como quiera que la responsabilidad que aquí se les imputa a los productores está engastada en el ámbito de una relación de consumo, vale decir, de producción de bienes y servicios para ser incorporados al mercado, no les será imputable el daño padecido por un consumidor cuando ellos no pusieron en circulación el producto, ora porque les fue sustraído o ya porque tal hecho obedeció a actos de piratería industrial o comercial. Independientemente de que en su momento el legislador establezca otras circunstancias o la Corte las advierta, lo cierto es que aquellos tampoco responderán cuando el defecto del producto se debe a que fue elaborado atendiendo las normas imperativas existentes, pues es tangible que éstas no dejan opción alguna al fabricante, quien, en ese orden de ideas se encuentra irremediablemente supeditado a la regulación estatal, circunstancia que impide atribuirles responsabilidad" (Corte Suprema de Justicia de Colombia, 2005). 
prema de Justicia de Colombia, 2009). Se puede evidenciar entonces, que algunos productos no ofrecen una "razonable seguridad a la que toda persona tiene legítimo derecho, y generan un daño a la integridad física o económica del consumidor; en estos casos la pretensión es que se le indemnicen los perjuicios generados por el producto defectuoso" (Robledo, 2013) causante de daños al paciente.

Otro potencial demandado es el importador por el hecho de "haber introducido el producto defectuoso a las fronteras nacionales, omitiendo la prudencia y diligencia que debe asumir antes de importarlo" (Corte Suprema de Justicia de Colombia, 2009). Por último, puede ser demandada la clínica u hospital donde se realizó el procedimiento, así como el profesional de la salud quien realizó la intervención quirúrgica generadora de daños.

El delito civil a cargo de quien importa y comercializa un producto defectuoso, como lo son las prótesis mamarias defectuosas, debe ser desvirtuado por la persona natural o jurídica legitimada por pasiva en la demanda pertinente. Producto que puede ser catalogado como defectuoso, por cuanto "no ofrece la seguridad que legítimamente se espera de él, condición que, en consecuencia se predica no por su falta de aptitud para el uso para el que fue adquirido, sino por no cumplir las condiciones de seguridad a que tiene derecho el público" (Corte Suprema de Justicia de Colombia, 2009) y en especial, los pacientes a quienes se les pueden implantar las presuntas prótesis averiadas.

Hay que establecer entonces, la probable falla en el servicio por parte del INVIMA a quien le corresponde la inspección, vigilancia y control de las prótesis defectuosas, cuando este ente de control actúe con negligencia por omisión al no actuar o hacerlo tardíamente o establecer si su actuación fue anómala. Lo anterior, se resume en que "la actividad del Estado en este título de imputación de responsabilidad, se enmarca en conductas positivas como en los casos en que la administración ha actuado mal, y en conductas omisivas para las circunstancias en que no haya actuado o ésta haya sido tardía"34 (Guechá, 2012, p. 99).

Lo precedente, entre otras razones, porque en un procedimiento quirúrgico en el cual al paciente se le realiza un implante mamario defectuoso, generalmente el citado procedimiento se realiza únicamente con la presencia del recurso humano en salud requerido, sin que la víctima y sus causahabientes o perjudicados por rebote, tengan la posibilidad de percatarse del hecho generador del daño antijurídico. No obstante, se está frente a un título de imputación de carga estática con presunción de falla en el servicio, y no de carga dinámica de la prueba; en este caso, a la víctima le corresponde probar como mínimo, las fechas en las cuales se le prestó el servicio médico-asistencial, y el daño generador de perjuicios que pretende sea indemnizado por parte del Estado o de la entidad particular prestadora del servicio.

En el caso de la responsabilidad del Estado por la potencial falla en el servicio a cargo del INVIMA como legitimado por pasiva, no sería válido argumentar que puede existir una falla relativa del servicio; denominada relativa, porque si bien debe existir un Estado ideal que proteja la vida y honra de los asociados, también existe un Estado real ${ }^{35}$ (Consejo de Estado de Colombia, 2006) al que se le puede aplicar la premisa: "nadie está obligado a lo imposible". En el tema de investigación, no aplica dicha relatividad porque se puede evidenciar en algunos casos, la ausencia de inspección, vigilancia y control por parte del INVIMA, razón por la

34 Como se indicó con anterioridad, puede presentarse en estas circunstancias la denominada falla anónima del servicio a cargo del Estado, porque los profesionales que intervienen en el procedimiento quirúrgico pueden ser los causantes del daño sin que se especifique quién es el potencial dañador.

35 Se señala en el citado fallo que "Se le exige al Estado la utilización adecuada de todos los medios de que está provisto, en orden a cumplir el cometido constitucional en el caso concreto; si el daño se produce por su incuria en el empleo de tales medios, surgirá su obligación resarcitoria; si el daño ocurre pese a su diligencia no quedará comprometida su responsabilidad" (Consejo de Estado de Colombia, 2006). 
cual el Estado debe reparar a las víctimas por los daños irrogados con su actuar negligente.

\section{LA PROTECCIÓN DEL PATRIMONIO DEL ESTADO Y DE LOS PRESTADORES EN SALUD PARTICULARES, A TRAVÉS DEL SEGURO DE RESPONSABILIDAD CIVIL}

El Estado y sus agentes médicos como potenciales generadores de daños tienen la facultad de celebrar un contrato de seguro de responsabilidad civil médico-sanitaria, con el objetivo de salvaguardar su patrimonio; patrimonio que integra un conjunto de activos a favor de los victimarios, que pueden verse comprometidos por las acciones judiciales presentadas por los pacientes dañados, a quienes se les implanten prótesis mamarias defectuosas. De igual forma, los médicos cirujanos plásticos particulares que realizan procedimientos de cirugía plástica estética o con fines reconstructivos, tienen la posibilidad de trasladar los riesgos a una compañía aseguradora, a cambio del pago de una prima o precio del seguro.

Como se ha venido señalando, la víctima de los implantes mamarios que resulten defectuosos, puede presentar acciones judiciales en contra del Estado, por responsabilidad administrativa bajo el título de imputación de falla en el servicio o iniciar demandas en contra de los particulares en su calidad de prestadores de salud privados, donde se les pueden implantar prótesis defectuosas. La demanda al Estado se puede generar por dos causas: la primera, por la negligencia por omisión por parte del INVIMA de sus funciones de vigilancia y control de un producto defectuoso y, la segunda causa, por los daños originados en su calidad de prestador en salud profesional liberal o ente sanitario, donde se le practique al paciente el procedimiento médico generador del evento adverso.

Los dos potenciales legitimados por pasiva tienen la facultad de trasladar los riesgos inherentes a su actividad, a una compañía aseguradora debidamente inspeccionada, vigilada $y$ controlada por la Superintendencia Financie$\mathrm{ra}^{36}$ (Superintendencia Financiera de Colombia, 2012); traslado que genera beneficios para las víctimas, porque será la compañía aseguradora la obligada a pagar los perjuicios producidos por el victimario, responsable del pago de la indemnización. Pago realizado, como consecuencia del acto jurídico bilateral conmutativo, celebrado entre la compañía aseguradora y el prestador en salud o ente estatal, en su calidad de tomador asegurado.

El seguro de responsabilidad civil constituye una garantía del pago de la obligación de indemnización a favor de las víctimas, por los perjuicios patrimoniales y extrapatrimonia$l_{e s}{ }^{37}$ ocasionados por el tomador asegurado, en la prestación de un servicio, en el suministro de un producto o la incorporación de un implante en el organismo del paciente; paciente que se constituye en beneficiario de la póliza de responsabilidad civil, para entes privados o públicos potenciales generadores de daños.

36 "Naturaleza Jurídica y Objeto. Naturaleza Jurídica: La Superintendencia Financiera de Colombia, es un organismo técnico adscrito al Ministerio de Hacienda y Crédito Público, con personería jurídica, autonomía administrativa y financiera y patrimonio propio. Objeto: El Presidente de la República, de acuerdo con la ley, ejercerá a través de la Superintendencia Financiera de Colombia, la inspección, vigilancia y control sobre las personas que realicen actividades financiera, bursátil, aseguradora y cualquier otra relacionada con el manejo, aprovechamiento o inversión de recursos captados del público. La Superintendencia Financiera de Colombia tiene por objetivo supervisar el sistema financiero colombiano con el fin de preservar su estabilidad, seguridad y confianza, así como, promover, organizar y desarrollar el mercado de valores colombiano y la protección de los inversionistas, ahorradores y asegurados. Funciones Generales. La Superintendencia Financiera de Colombia ejercerá las funciones establecidas en el decreto 2739 de 1991 y demás normas que la modifiquen o adicionen, el Decreto 663 de 1993 y demás normas que lo modifiquen o adicionen, la Ley 964 de 2005 y demás normas que la modifiquen o adicionen, las demás que señalen las normas vigentes y las que le delegue el Presidente de la República" (Superintendencia Financiera, 2012).

37 Los perjuicios patrimoniales están representados en el daño emergente y el lucro cesante y los extrapatrimoniales como género lo contienen las especies de perjuicios morales, a la salud, fisiológicos, estéticos y pérdida de la oportunidad. 
Las compañías de seguros, personas jurídicas especializadas en la asunción de riesgos, son entes que ofrecen protección al patrimonio de los prestadores en salud ${ }^{38}$ (Arias, 2010) públicos o privados, con amparos de las siguientes coberturas: la cobertura por ocurrencia, y la cobertura por descubrimiento o reclamación. El seguro por reclamación o también denominado claims made se originó en los países anglosajones y específicamente en los Estados Unidos de América, como consecuencia de los perjuicios generados por los denominados $d a-$ ños diferidos, donde el hecho dañoso se exterioriza después de transcurrido un lapso de tiempo considerable, como en el caso de los implantes mamarios defectuosos.

Algunos implantes que pueden ser defectuosos, se pueden romper dentro del organismo de la paciente con posterioridad a la realización del procedimiento quirúrgico, con la consecuente generación de eventos adversos, los cuales se pueden descubrir o aparecer con posterioridad a la ocurrencia del hecho dañoso; hecho generador de eventos adversos, que inclusive puede haberse presentado con anterioridad a la fecha de la celebración del contrato de seguro.

En los seguros de responsabilidad civil para prestadores en salud, se ofrece también la cobertura por ocurrencia, que para el caso de los victimarios de los implantes defectuosos, sería inapropiada. La inconveniencia de este tipo de cobertura, se debe a la posible vulneración del patrimonio del dañador, en el evento de acordarse que el daño debe exteriorizarse dentro de la vigencia y no cuando el hecho dañoso

38 Para el caso de la presente investigación, se entiende como condición general del seguro de responsabilidad civil médica,

(...) el ejercicio de la profesión médica del asegurado, legalmente autorizado para ejercerla, indicada en la solicitud del seguro y en la carátula de la póliza. La presente póliza se extiende a cubrir la responsabilidad civil del asegurado, imputable a este por actos y omisiones cometidos en el ejercicio de una actividad profesional médica, por el personal médico, paramédico, médico auxiliar, farmacéutico o laboratorista que se encuentre al servicio y bajo la supervisión del asegurado, vinculado con éste mediante contrato laboral (Arias, 2010). se presente por fuera de la misma. En este caso, existe cobertura si la prótesis mamaria se rompe causando lesiones al paciente dentro de la vigencia del contrato, pero si el evento adverso se exterioriza o se revela fuera de la vigencia del contrato primigenio con cobertura por ocurrencia, el asegurador tiene la facultad de objetar el pago del siniestro:

Tales fenómenos suelen presentarse con alguna regularidad en relación con los seguros de responsabilidad civil por contaminación, en los seguros de responsabilidad profesional médica, en los seguros de responsabilidad por productos defectuosos, responsabilidad civil de Directores y Administradores y responsabilidad civil por errores y omisiones, entre otros (BBM Fasecolda, 2012).

Para garantizar la efectiva protección del patrimonio del victimario $y$, a su vez, responder por el pago de la indemnización a las víctimas, se debe establecer en el seguro de responsabilidad civil la cobertura adicional claims made ${ }^{39}$ (Contreras, 2006); este tipo de cláusulas adicionales representan una limitación a la cobertura otorgada por la compañía de seguros, de manera que la aseguradora asume la atención de los siniestros cuando se presentan y exteriorizan dentro de la vigencia del contrato o, en su defecto, con posterioridad a la terminación de la vigencia primigenia del mismo (Ordoñez, 1998).

Para el caso de los cirujanos plásticos estéticos o con fines reconstructivos, las cláusulas claims made operarían según los siguientes parámetros:

39 "La cláusula claims made ha surgido para restringir la cobertura de la póliza sólo a los siniestros ocurridos y denunciados durante su vigencia como forma para resolver los problemas de incidencia o índole económica que la siniestralidad del ramo ha ido presentando para la industria aseguradora." Y más adelante "En síntesis la cláusula claims made, consiste en una estipulación en virtud de la cual las partes en el contrato pactan que sólo están cubiertos los siniestros que, no solo hayan ocurrido, sino que también hayan sido reclamados a la compañía aseguradora, dentro del término cronológico de vigencia de la póliza" (Contreras, 1996). 
1. Cobertura de siniestros cuando el evento adverso se realice y avise al asegurador durante la vigencia del seguro, con el objetivo de que exista un amparo válido y nazca la obligación positiva de dar -pagar- a cargo del asegurador. Si el implante mamario defectuoso se deteriora y causa daños al organismo del paciente dentro del término de la vigencia del seguro, un año por ejemplo, dicho daño debe exteriorizarse y ser avisado dentro de la vigencia del contrato, para que opere el amparo respectivo porque, de lo contrario, no existe cobertura.

2. En las citadas cláusulas, se puede establecer que nace la obligación condicional del asegurador, siempre que en el transcurso de la vigencia del contrato se presenten los siguientes eventos:

a. El hecho médico-sanitario culposo o doloso, que puede limitar las facultades físicas y psíquicas del paciente, se reitera, siempre que el hecho se realice dentro de la vigencia de la póliza.

b. El aviso de siniestro a la compañía por parte del tomador asegurado prestador en salud, debe presentarse dentro de la vigencia del seguro de responsabilidad civil.

c. La reclamación extrajudicial o demanda judicial presentada por la víctima como interviniente beneficiaria de la póliza, debe presentarse dentro del término de vigencia contado desde la fecha de celebración del contrato hasta la terminación del mismo. Para que exista cobertura en este tipo de negocio jurídico, deben concurrir los tres eventos antes señalados, para que el asegurador pague los perjuicios causados al paciente dañado, en la realización de un procedimiento de implante mamario que puede resultar defectuoso.

3. El hecho médico sanitario dañoso, en el caso de la investigación el procedimiento de implante mamario defectuoso, debe presentarse dentro de la vigencia del se- guro, así como también se debe surtir la reclamación por parte del paciente víctima del daño galénico, dentro de la vigencia del seguro e inclusive fuera de ésta. Por ende, la prótesis mamaria puede implantarse dentro de la vigencia del contrato, el daño exteriorizarse dentro de la citada vigencia, pero la cobertura se puede extender a las reclamaciones presentadas por la víctima, aún terminada la vigencia acordada en la póliza. En este caso, habría cobertura en el evento en que el paciente beneficiario del seguro reclame el pago de la indemnización con posterioridad a la terminación del contrato de seguro de responsabilidad civil, celebrado entre el prestador sanitario y el asegurador.

Cabe anotar que este tipo de cobertura, además de los prestadores en salud, la pueden requerir los productores y comercializadores de productos como las prótesis mamarias; lo anterior, porque estos tienen la obligación de garantizar las condiciones de idoneidad, calidad y seguridad respectivas, sin que por ello se exija contraprestación alguna (Congreso de la República de Colombia 2012) al consumidor de sus productos, lo que contraviene el principio de relatividad (Villalba, 2011) de los contratos $^{40}$ (Tamayo J, 2012), por efectos de la obligación plural solidaria y no plural conjunta. Por ende, no se aplica el principio res

40 En cuanto a la prestación de los servicios médicos, que abarca los prestados por los cirujanos plásticos estéticos a quienes se les aplicaría la nueva ley del consumidor, se señala lo siguiente: "el problema es que el estatuto, equivocadamente, comprende la prestación de servicios médicos, jurídicos y de profesiones liberales en general. También comprende los servicios de seguros y de transporte. Problema que se agudiza cuando el artículo 16 establece que, en caso de incumplimiento de las garantías de calidad y eficiencia, el demandado se exonera mediante la prueba de una causa extraña. En consecuencia, los médicos, los abogados y en general los mandatarios, serán responsables objetivamente si el resultado obtenido no era el buscado por el consumidor. No obstante, el artículo $7^{\circ}$ en su inciso segundo, consagra una oscura norma que pareciera corregir la equivocación de hacer responder a los médicos y a los abogados objetivamente". (Tamayo J, 2012) 
inter alios acta aliis nec nocet nec prodest ${ }^{41}$ porque, si bien es cierto la convención no se celebró de manera directa entre el productor o comercializador de la prótesis y el paciente, se configura entre ellos una obligación plural solidaria.

\section{CONCLUSIONES}

Se encontró, en la investigación bibliográfica realizada, que a los usuarios de los servicios de procedimientos de implantes mamarios que pueden resultar defectuosos se les pueden generar daños en su vida e integridad física y psíquica.

Entre los hallazgos, se estableció que si el ente estatal actuó con negligencia por omisión en las funciones de inspección, vigilancia y control, en este caso a cargo del Instituto Nacional de Vigilancia de Medicamentos y Alimentos (INVIMA), pudo haber existido responsabilidad del Estado por falla en el servicio. Esta entidad pública que pudo ser negligente en el análisis técnico y científico de un producto potencialmente defectuoso, el cual generó daños transgresores de los derechos de los pacientes, usuarios de los servicios de cirugía plástica con fines estéticos o reconstructivos.

En la investigación se identifica que a través de la celebración de un contrato de seguros de responsabilidad civil con cobertura adicional claims made, es posible proteger el patrimonio de los victimarios tomadores asegurados, así como también garantizar el pago de la indemnización de manera integral, en favor de las víctimas constituidas como beneficiarias del seguro. Victimarios asegurados que pueden ser entes de salud públicos, privados o profesionales liberales, que realizan procedimientos de cirugía plástica estética o con fines reconstructivos.

41 Significa que un contrato que la vez es una convención, no surte efecto sino en relación con las partes que han intervenido en la convención.

\section{REFERENCIAS}

Adserá, A. (2009/10/18). Imagen por resonancia magnética nuclear: RMN. Extraído diciembre 15, 2012, desde http://www.enciclopediasalud.com/categorias/cuerpo-humano/articulos/imagen-por-resonancia-magnetica-nuclear-rmn

Alarcón, O. (2012/02/08). Implantes mamarios de silicona PIP. Extraído diciembre 12, 2012, desde http://www.ovidioalarcon. com.co/2012/02/08/implantes-mamariosde-silicona-pip/.

Arias, L. (2010). Principales aspectos del contrato de seguro de responsabilidad civil profesional en relación con la responsabilidad médica. Revista e-Mercatoria, 9, 1.

Bejarano, R. (1994). Intervención de terceros y medidas cautelares en el proceso arbitral. Revista del Instituto colombiano de derecho procesal, 2, 16,17.

Calabresi, G. (1961). Some thoughts on risk distribution and the Law of Torts. Yale Law Journal 70.

Castro, C. (2012, Marzo 2). Implantes, el juicio del año. Ámbito Jurídico.

Código Civil colombiano [Cod.] (2011). Bogotá.

Código Contencioso Administrativo de Colombia [Cod.] (2011). Bogotá: Ed. Legis S.A.

Consejo de Estado de Colombia, Sección Tercera, Sala de los Contencioso Administrativo. Expediente 19963 de 2011 (CP. Danilo Rojas Betancourth; Mayo 28 de 2011).

Consejo de Estado de Colombia. Consejo de Estado. Sección Tercera, Sala de lo Contencioso Administrativo (CP. Carlos Portocarrero Mutis; abril 28 de 1967). 
Consejo de Estado de Colombia. Sección Tercera, Sala de lo Contencioso Administrativo. Expediente 6754 de 1992 (CP. Carlos Betancur Jaramillo; agosto 24 de 1992).

Consejo de Estado de Colombia. Sección Tercera, Sala de lo Contencioso Administrativo, Expediente 16.626 de 2006 (CP. Alier Hernández Enríquez; noviembre 30 de 2006).

Consejo de Estado de Colombia. Sección Tercera. Sala de lo Contencioso Administrativo. Expediente 17.303 de 2009 (CP. Ruth Stella Correa; febrero 25 de 2009.

Constitución Política de Colombia [Const.]. Julio 7 de 1991 (Colombia).

Contreras, O. (1996). De la cláusula claims made en los seguros de responsabilidad civil. Revista Ibero-Latinoamericana de Seguros, 8, 105.

Corte Constitucional de Colombia, sentencia C-370 de 2006, M.P. Manuel José Cepeda Espinosa, Jaime Córdoba Triviño, Rodrigo Escobar Gil, Marco Gerardo Monroy Cabra, Álvaro Tafur Galvis, Clara Inés Vargas Hernández.

Corte Constitucional de Colombia, sentencia C-409 de 2009, M.P. Juan Carlos Henao Pérez. Expediente D-7478.

Corte Constitucional de Colombia, sentencia T- 534 de 1992, M.P. Ciro Angarita Barón.

Corte Constitucional de Colombia, sentencia T-484 de 1992, M.P. Fabio Morón Díaz.

Corte Constitucional de Colombia, sentencia T-534 de 1992, M.P. Ciro Angarita Barón.

Corte Constitucional de Colombia. Sentencia C-1140 de 2000 (MP. José Gregorio Hernández Galindo).
Corte Constitucional de Colombia. Sentencia C-228 de 2002 (MP. Manuel José Cepeda, Eduardo Montealegre; abril 3 de 2002).

Corte Constitucional de Colombia. Sentencia C-370 de 2006 (MP. Manuel José Cepeda Espinosa ed, al; mayo 18 de 2006).

Corte Constitucional de Colombia. Sentencia C-409 de 2009 (MP. Juan Carlos Henao Pérez; junio 17 de 2009).

Corte Constitucional de Colombia. Sentencia T- 534 de 1992 (MP. Ciro Angarita Barón; septiembre 24 de 1992).

Corte Constitucional de Colombia. Sentencia T-484 de 1992 (MP. Fabio Morón Díaz; agosto 11 de 1992).

Corte Constitucional de Colombia. Sentencia T-597 de 2001 (MP. Rodrigo Escobar Gil; Junio 7 de 2001).

Corte Constitucional, sentencia C-228 de 2002, M.P. Manuel José Cepeda, Eduardo Montealegre.

Corte Suprema de Justicia de Colombia. Sala de Casación Civil. Expediente exp. 2589931030021999-00629-01 de 2009 (MP. Pedro Octavio Munar Cadena; abril 30 de 2009).

Decreto 1290 de 1994. Diario Oficial No. 41.406 del 24 de junio de 1994. Ministerio de Gobierno de la República de Colombia. Viceministerio de Salud.

Dudgale, D. (2011/05/22). Mielina-Overview. Extraído diciembre 12, 2012, desde http:// es.mimi.hu/medicina/mielina.html.

Fernández, M. (2008). La responsabilidad médica: Problemas actuales. Bogotá: Ibañez. 
Galindo, J. (2011). La salud y su aseguramiento en Argentina, Chile Colombia y España. Madrid: Editorial Fundación Mapfre.

Guechá, C. (2012). La falla en el servicio: Una imputación tradicional de responsabilidad del Estado. Revista Prolegómenos - Derechos y Valores Universidad Militar Nueva Granada, 29, 102.

Hontanilla, B. (2012/06/13). Director de Cirugía Plástica, Reparadora y Estética de la Clínica Universidad de Navarra. Extraído noviembre 25, 2012, desde http://www.abc. es/20120105/sociedad/abci-implantes-mamarios-201201041912.html

Ibarra, G. (2012, Septiembre 7). El nuevo proceso en materia de protección al consumidor. Periódico Ámbito Jurídico.

Instituto Nacional de Vigilancia de Alimentos y Medicamentos INVIMA. Extraído enero 15, 2013, desde http://web.invima.gov.co/portal/faces/index.jsp?id=1172

Le Tourneau, P. (2006). La responsabilidad civil profesional. Bogotá: Editorial Legis. 2006.

Ley 100 de 1993. Diario Oficial No. 41.148 de 23 de diciembre de 1993. Por la cual se crea el sistema de seguridad social integral y se dictan otras disposiciones.

Ley 1480 de 2011 Por el cual se expide el Estatuto del Consumidor. Diario Oficial No. 48.220 del 12 de octubre de 2011. Congreso de la Republica de Colombia.

López, J. (2007, Septiembre). El Derecho a la salud como derecho fundamental. Laboratorio Actual. Asociación de Bacteriólogos Javerianos, 40, 33-36.

Macklin, R. (2009). Dignity is a useless concept. BMJ Group, 327, 1420.
Oficina del Alto Comisionado de las Naciones Unidas. Declaración sobre los principios fundamentales de justicia para las víctimas de delitos y del abuso de poder. Extraído noviembre 20, 2012, desde http://www2.ohchr.org/ spanish/law/delitos.htm

Olano, H. (2011). Constitución Política de Colombia. Bogotá: Doctrina y Ley.

Ordoñez, A. (1998). El Contrato de Seguro. Ley 389 de 1997 y otros estudios. Bogotá: Universidad Externado de Colombia.

Organización de las Naciones Unidas (ONU). (1985/11/29). Oficina del Alto comisionado de las Naciones Unidas para los Derechos Humanos. Declaración sobre los principios fundamentales de justicia para las víctimas de delitos y del abuso de poder; adoptada por la Asamblea General en su resolución 40/34. Extraído noviembre 30, 2012, desde http:// www2.ohchr.org/spanish/law/delitos.htm

Organización de las Naciones Unidas. Declaración Universal de los Derechos Humanos. Extraído diciembre 10, 2012, desde http:// www.un.org/es/documents/udhr/

Organización Mundial de la Salud (OMS). (2007, Agosto). El Derecho a la Salud: Centro de Prensa, 323.

Paillet, M. (2001). La Responsabilidad Administrativa. Bogotá: Editorial Universidad Externado de Colombia.

Parra, J. (1992). Derecho Procesal civil. Parte General. Tomo I. Bogotá: Editorial Temis.

Resolución 1446 de 2006. Por la cual se define el Sistema de Información para la Calidad y se adoptan los indicadores de monitoria del Sistema Obligatorio de Garantía de Calidad de la Atención en Salud. Mayo 8 de 2006. Ministerio de Protección Social. 
Robledo, P. (2013, Enero 15). Consumo seguro. Periódico Ámbito Jurídico.

Rojas, J. \& Coronado, S. (2009, Diciembre). Novedades Jurisprudenciales: La responsabilidad del productor y el distribuidor por productos defectuosos. Universitas. Pontificia Universidad Javeriana, 6, 325.

Ruiz, W. (2010). Responsabilidad del Estado y su Regímenes. Bogotá: Ecoe Editores.

Saavedra, R. (2005). La Responsabilidad Extracontractual de la Administración Pública. Bogotá: Editorial Gustavo Ibáñez.

Superintendencia Financiera de Colombia. Extraído enero 15, 2013, desde http://www. superfinanciera.gov.co/
Tamayo, A. (2005). La responsabilidad civil contractual y la extracontractual. Bogotá: Ediciones Doctrina y Ley.

Tamayo, J. (2012, Marzo 12). La responsabilidad civil en el nuevo Estatuto del Consumidor. Periódico Ámbito Jurídico.

Trigo, F. \& Stiglitz, R. (1983). El seguro contra la responsabilidad civil profesional del médico. Buenos Aires: Editorial ASTREA.

Villalba, J. (2012). Introducción al Derecho de Consumo. Bogotá: Universidad Militar Nueva Granada. 